\title{
Task Shifting and Innovative Medical Education - Moving Outside the Box to Serve Rural Nepal
}

\author{
Zimmerman $M^{\top}$ \\ 'Nick Simons Institute, Kathmandu, Nepal.
}

\section{ABSTRACT}

Health care systems everywhere must tackle the problem of supplying quality health care workers to underserved areas. Except in countries that are both small and wealthy, the traditional methods of medical education and worker deployment have proven widely inadequate - and this is certainly the case in Nepal. We discuss here how alternative approaches to remedy the problem are being undertaken locally. First, we show how the concept of task-shifting to lower level staff has already begun to fill in gaps in the area of emergency obstetric care. In the short- and medium-term, taskshifting is a viable solution to the mal-distribution of health care workers. Second, we give three short case studies that illustrate a small, local organization, Nick Simons Institute, partnering with the government's National Health Training Center to pioneer 'outside the box' alternatives to medical education. These include the design and implementation of novel in-service courses, including CME.

Key Words: medical education, rural health care worker, task-shifting

\section{INTRODUCTION}

Countries around the world are facing a health care worker crisis. The World Health Organization (WHO) has joined health ministries and other development partners to give this issue high priority. ${ }^{1,2}$ This paper highlights the human resource for health $(\mathrm{HRH})$ situation in the country of Nepal - focusing on how certain local initiatives in task-shifting and innovative medical education are beginning to bear fruit.
We will begin by providing a cursory background of the country's health situation. For illustration, we'll use the example of district-level comprehensive obstetric care, which can be a proxy for successful delivery of health care services in general.
Correspondence:

Dr. Mark Zimmerman

Nick Simons Institute

Box 8975; EPC 1813

Jhamsikhel, Lalitpur Nepal.

Email: markz@nsi.edu.np

Phone: 977-1-5013502 


\section{Nepal's Health Situation}

According to WHO Core Health Indicators, Nepal ranks at the lower end of South-East Asia Region (SEAR) countries. ${ }^{3}$ As of 2005 , its maternal mortality ratio (MMR) and proportion of births attended by skilled personnel were each last among 11 SEAR countries. While there have been gains in Nepal's country-wide statistics, such as a dramatic decline in MMR between 2001 and 2006 surveys, these sometimes mask the problem of lingering poor health among large populations who live in rural districts. ${ }^{3}$ The Nepal Government's Health Sector Reform Strategy ${ }^{4}$ points the way towards improvement through the program outputs of (1) Delivery of essential health care services (particularly maternal-child health); (2) Decentralized management; and (3) Public-private partnerships. This Strategy - along with other Health Ministry plans - emphasizes the pressing need to improve national policies in human resource management.

The Nepal Health Ministry aims by 2017 to have all its districts providing comprehensive obstetric services and by 2011 to have trained 5000 skilled birth attendants. As of 2009 , only $21 \%$ of government rural district hospitals can regularly perform cesarean sections and only $15 \%$ of the short-term SBA training goal has been met. ${ }^{5}$ This slow progress occurs in spite of a decade of mushrooming of the number of medical colleges and nursing campuses in the country. According to WHO data, Nepal has 2.0 physicians / 10,000 population, which ranks it eighth in the region. ${ }^{3}$

Nevertheless, there are reasons for optimism. Under the direction of the Department of Health Services, the government's National Health Training Center (NHTC) directs a growing number of training programs that emphasize rational selection of cadre for training, modern learning approaches, and well-structured national norms. The Health Ministry, sometimes in the face of professional opposition, has courageously moved towards task-shifting - recognizing that within this conceptual change lie the only short- and medium-term solutions to the problem of providing adequate rural health care.

\section{Task-Shifting}

In January 2008 in Addis Ababa, the WHO conducted the First Global Conference on Task-Shifting. ${ }^{6}$ The AIDS crisis in Africa drove this initiative and expansion of the HIV/AIDS-related work force naturally consumes a lion's share of attention. That notwithstanding, task-shifting is neither a new concept, nor limited to the developing world, nor is it disease-specific. ${ }^{7,8}$ Task-shifting is defined simply as the rationale redistribution of tasks among the health workforce team. ${ }^{6}$ To site just one example among thousands: in many rural areas of the United States nurse anesthetists are the solo providers of anesthesia services; without them, in many U.S. hospitals operations would not take place. It's important to note that world geopolitical belts vary in their acceptance of task-shifting. Generally speaking, the U.K. - with India continuing to follow suit - is relatively traditional in maintaining a specialist doctor-centered model of curative health care provision. This approach may work in geographically small countries with plentiful resources, but in the rest of the world it breaks down into peak coverage for the privileged few.

By their sustained presence at the village level, mid-level health care workers form the back-bone of the health care service in Nepal's districts. Shifting tasks from absentee doctor to long-serving medical assistant has occurred (and will continue to occur) across the country for a range of medical tasks. Here I'd like to focus on the cesarean section (CS) - a single medical event, for which an integrated team needs to be simultaneously present. I've not chosen this procedure because it is the solitary aspect of running a district hospital, but rather because the proposed team providing $24 / 7$ CS coverage can usually perform a range of other essential medical services: like conducting emergency operations, reducing fractures, performing difficult deliveries, running a general outpatient clinic and assorted others. CS is a good proxy.

In the attached table, are listed five task components centered on performing cesarean section. In Kathmandu, as in other capital cities of the world, each of these tasks is usually the domain of an upper level health care worker. In fact, one may find those very specialist doctors stridently protecting their turf from the perceived threat of task shifting. The table below shows that maintaining this traditional approach would result in markedly limited obstetric service in Nepal's district hospitals. Even the most optimistic traditionalist would have to admit that specialist doctor numbers could only be scaled up to fill these district-level gaps in the very distant future.

The highlighted area shows Nepal's Health Ministry migration towards an alternate approach. The captain of this team is Nepal's Family Practice Doctor (MDGP), who has training in all areas with strong emphasis on surgical and obstetric skills. While MDGPs haven't been uniformly successful in transforming district hospitals into surgical centers, this has often been due to the absence of a complete, complementary team. All of the training courses listed below are run under the auspices of the Nepal government, though mission and NGO hospitals also participate as training sites. 
In its Task Shifting Global Recommendations and Guidelines ${ }^{6}$, the WHO raises several cautions: (1) Identify appropriate tasks; (2) Develop a regulatory environment; (3) Standardize training programs; (4) Create a mechanism to finance the increased costs. To varying degrees, Nepal's Health Ministry is working in each of these areas. However, as with many countries, Nepal moves slowly towards the day when it fully embraces a program of task shifting. Nepal's government needs to give priority to the creation of new posts for these alternate providers (foremost, for the MDGP), without which formation of 'complete health care teams' will remain an elusive goal.

Table 1. Task Shifting in Nepal District Hospitals (2009)

\begin{tabular}{|c|c|c|c|c|c|}
\hline Task & $\begin{array}{l}\text { Traditional } \mathrm{Pr} \\
\text { Provider Rura } \\
\mathrm{Di}\end{array}$ & $\begin{array}{l}\text { Present in } \\
\text { Rural Hospita } \\
\text { District\# }\end{array}$ & $\begin{array}{l}\text { Alternate Pr } \\
\text { tals Provider Rur } \\
\text { \# Hospitals } \\
\text { (/62 total) }\end{array}$ & $\begin{array}{l}\text { Present in } \\
\text { Rural District }\end{array}$ & $\begin{array}{l}\text { Nepal Training } \\
\text { Course Length } \\
\text { (Yr. Estab.) } \\
\text { (/62 total) }\end{array}$ \\
\hline Operate & $\begin{array}{l}\text { Obs/Gyne } \\
\text { Doctor }\end{array}$ & 3 & $\begin{array}{c}\text { MDGP } \\
\text { (Family Prac.) } \\
\text { Doctor }\end{array}$ & 11 & $\begin{array}{l}3 \text { yrs. } \\
(1982)\end{array}$ \\
\hline Anesthetize & $\begin{array}{l}\text { ze Anesth } \\
\text { Doctor }\end{array}$ & 0 & $\begin{array}{c}\text { Anesthesia } \\
\text { Asst. }\end{array}$ & 20 & $\begin{array}{c}\text { 6/12 mos. } \\
(2003)\end{array}$ \\
\hline Deliver & $\begin{array}{l}\text { OGDoc/ } \\
\text { Midwife }\end{array}$ & 3 & $\begin{array}{c}\text { SBA-Staff or } \\
\text { Aux Nurse }\end{array}$ & 62 & $\begin{array}{c}2-8 \text { wks. } \\
(2006)\end{array}$ \\
\hline Ultrasoun & Ind Radiologist & ist 0 & $\begin{array}{l}\text { MDGP (Family } \\
\text { Prac.) Doctor }\end{array}$ & $\begin{array}{l}\text { ly } \\
\text { pr }\end{array}$ & $\begin{array}{l}3 \text { mos. } \\
(2008)\end{array}$ \\
\hline Equipmer & entEngineer & A & $\begin{array}{c}\text { Biomedical } \\
\text { Assistant Tech }\end{array}$ & $\mathrm{ch}^{29}$ & $\begin{array}{l}2 \text { mos. } \\
(2009)\end{array}$ \\
\hline
\end{tabular}

Many organizations in Nepal continue to try the 'trickl down' approach to the rural health care problem. This involves building more medical and nursing schools, selecting rural students, and devising new, improved undergraduate curricula. Unfortunately, around the world these methods have not met with success and they are unlikely to succeed in Nepal. The problem requires paradigm shifts in thinking and courageous leaders to implement these pioneering programs. Task-shifting offers itself as a viable short- and medium-term solution.

\section{Three Innovations in Medical Education}

Nepal's health care leaders have made significant advances in pre-service education. While not discounting those gains, I would rather like to focus here on several innovations made in the area of in-service education. The lead division in charge of in-service education in Nepal's Ministry of Health and Population is the National Health Training Center. The NHTC director, Mr. Arjun Singh, brings vision and positive energy to the government's human resource challenges. He and his team are at the center of two of the three case studies that I've chosen to present here.
Each of these case studies shows a progression from an initial idea to field testing to curriculum development to piloting to refining to scaling up.

\section{Case Study 1. A Virtual Training Institute}

While Nepal has made significant strides in undergraduate and post-graduate doctor education, the country has lagged behind in addressing the ongoing need for its fully qualified doctors to keep up to date. Continuing professional development for doctors is mainly restricted to intermittent dinner programs and conferences that are over-filled with didactic presentations.

With this situation in mind, in 2007 we formed a CME Technical Advisory Group which included the WHO's Professor M.M.Huq among other medical luminaries in Nepal. That group oversaw a CME needs assessment among 212 general doctors in 51 districts, which identified the needs, aspirations, and IT capacity of doctors around the country.

Based on that data, a core team of Nepal-based authors collaborated with the organization WorldCME to produce Nepal's first distance education CME course. Nepal CME is a 7-module set, with each subject presented on a CD ROM (Adult Emergency, Pediatric Emergency, Obstetrics, Chronic Medicine, Dermatology, Psychiatry, and Infectious Disease). Instruction is entirely case-based - the patients usually Nepali - with cases rolling out in an interactive format on the computer. At the end of the module, the student must take a multiple choice exam and fill in a self-evaluation form to receive credit. Nepal CME is sold for 400 rupees (\$6) per CD ROM.

Sixty four doctors enrolled during the initial pilot period; to date 180 doctors have enrolled. During a 6-month pilot period, $42 \%$ of doctors fully completed four modules with passing marks. While there was wide acceptance of the content and modality of the teaching, doctors cited the problems of inadequate time, power cuts, and 'laziness' as obstacles to completing the full course.

The main future challenge for the NepalCME team lies not in producing a good learning package. Rather, we face the task for lobbying for changes in the national attitude towards doctors' CME. Nationallevel policy changes will probably be needed in order to increase 'demand' for such products. 


\section{Case Study 2. Mid-Level Practicum}

In 2006, the NHTC identified a gap in the clinical skills of its mid-level district health care workers (health assistants and auxiliary health workers). The NHTC Director approached a new organization, Nick Simons Institute (NSI), about working together to develop an in-service course to address this problem. In 2007, the two organizations conducted a focused clinical skills assessment of 168 government mid-level workers. Based on the measured competency gaps, in $2008 \mathrm{NSI}$ and NHTC produced a pioneering course called Mid-Level Practicum. Some its features are:

- Centered on the most common 20 chief complaints and 10 procedures at district level.

- Clinical decision making taught using history-based algorithms in hand book form that the student takes back to his practice with him.

- Competency-based: using checklist learning guides in lab and clinic.

- Extensive clinical exposure in good hospitals.

During the first two pilot batches of training, using Objective Structured Clinical Examinations (OSCE), 32 students improved from average scores of $37 \%$ to $93 \%$. We hope that this course will be absorbed into the national training scheme for mid-level health care workers beginning in 2010 .

\section{Case Study 3. Nepal CMEa}

Nepal has major gaps in its health manpower and is trying to address these through scaling up health care training - pre-service and in-service. In a public-private partnership, the Health Ministry's National Health Training Center (NHTC) has welcomed collaboration with non-government health care institutions in order to supplement the training output of government hospitals and regional training centers.

The Nick Simons Institute (NSI) was established in 2006 with a mission to train and support rural health care workers. Rather than functioning as a self-contained medical-education complex, NSI has formed a network of medical institutions across the country and has worked to build these partners into excellent training sites for NHTC courses. This paradigm shift means that NSI is involved in site standardization, training of trainers, provision of additional staff salaries, training, equipment, and hostel space, as well as ongoing supervision of the site. While NSI facilitates, our training partners conduct the actual training and also earn income from tuition.

$\mathrm{NSI}$ and its nine partners (which span the country, east to west) are now involved in the five trainings Skilled Birth Attendant Anesthesia Assistant, Biomedical Equipment Technician, Ultrasound Training, and Mid-Level Practicum. These are all government trainings and $95 \%$ of students are government workers.

Within three years of starting, this model of an external development partner taking responsibility for (but not ownership of) additional training sites has begun to bear fruit. Our partnership with the Health Ministry remains active and continues to evolve into new areas.

Providing health care workers to rural areas has remained an elusive problem. Traditional methods of health education and worker deployment have produced limited or no success across many different countries. Innovative approaches to medical education can go hand-in-hand with pioneering work in task-shifting, providing training programs that fit well with the acute human resource needs of the country.

\section{CONCLUSIONS}

Task-shifting has proven to be an effective short-term solution to the health care worker crisis in Nepal and longterm policies should begin to incorporate it in the national health care strategy.

We present here three examples of innovation in medical education into Nepal and invite discussion (and collaboration) with other interested organizations in the region.

\section{ACKNOWEDGEIMENTS}

The author wishes to acknowledge the excellent and timely support of Rabina Shakya for her investigation of staffing numbers.

\section{REFERENCES}

1. Chen L, Evans T, Anand S, Boufford JI, Brown H, Chowdhury $\mathrm{M}$, et al. Human resources for health: overcoming the crisis. Lancet. 2004 Nov 27-Dec 3;364(9449):1984-90.

2. World Health Organization. The world health report 2006: Working together for health. Switzerland: WHO Geneva; 2006.

3. World Health Organization. Core health indicators - Website. [online]. 2005 [cited 2009 oct]. Available from: URL:http://apps.who.int/whosis/database/core/core_sele ct.cfm.

4. Government of Nepal. Health sector reform strategy: agenda for reform. Kathmandu: Ministry of Health; 2004.

5. Nepal Ministry of Health and Population. Family Health Division field statistics. Kathmandu: FHD; 2009.
6. World Health Organization. Task shifting: rational redistribution of tasks among health workforce teams. Global recommendations and guidelines. Geneva, Switzerland, WHO, Health Systems and Services. [online] 2007. [Cited 2009 Oct 15]. Available from:URL:http://www.who.int/ healthsystems/TTR-TaskShifting.pdf.

7. Chang L. Task shifting: a solution for the health worker human resource crisis? Medscape. [online]. 2009; [Cited 2009 Oct 15]. Available from:URL:http:/ / www.medscape.com/viewarticle/ 705727.

8. World Health Professions Alliance. Joint health professions statement on task shifting. Website. [online] 2008. [Cited 2009 Oct 15]. Available from:URL:http:/ / www.hrhresourcecenter.org/ node/1861. 